\title{
Short courses of daily prednisolone during upper respiratory tract infections reduce relapse frequency in childhood nephrotic syndrome.
}

\author{
Abeyagunawardena AS ${ }^{1}$, Thalgahagoda $\mathbf{R S}^{1}$, Dissanayake $\mathbf{P V}^{1}$, Abeyagunawardena $\mathrm{S}^{2}$, \\ Illangasekera $\mathbf{Y A}^{3}$, Karunadasa UI', Trompeter $\mathbf{R S}^{4}$ \\ ${ }^{1}$ Department of Paediatrics, Faculty of Medicine, University of Peradeniya, Sri Lanka \\ ${ }^{2}$ Department of Medicine, Teaching Hospital Peradeniya, Sri Lanka \\ ${ }^{3}$ Department of Pharmacology, Faculty of Medicine, University of Peradeniya, Sri Lanka \\ ${ }^{4}$ University College London, Centre for Nephrology, Royal Free Campus, United Kingdom \\ Corresponding Author - Professor Asiri Samantha Abeyagunawardena \\ Postal address _ - Department of Paediatrics \\ Faculty of Medicine \\ University of Peradeniya \\ Peradeniya \\ Sri Lanka \\ Email address - asiriabey26@gmail.com \\ Tel. number $\quad$ - 0094777843848
}

Keywords: viral respiratory infections, steroid-sensitive nephrotic syndrome, relapse, prednisolone

Word count - 2443 words 


\begin{abstract}
Background - Relapses of childhood nephrotic syndrome (NS) are frequently precipitated by viral upper respiratory tract infection (URTI). A review of the literature reveals that in patients with steroid dependent NS on alternate day corticosteroids, a short course of daily corticosteroid therapy during the course of an URTI may reduce relapse frequency.
\end{abstract}

Objective - To assess the effect of a short course of low dose corticosteroid therapy during the course of an URTI on relapse frequency in patients with steroid sensitive NS who have not been taking any treatment for a minimum period of 3 months.

Method - A double blind placebo-controlled crossover trial was conducted on 48 patients with idiopathic NS who had not been receiving corticosteroid therapy for a minimum of three months. Patients were randomized into two groups. Group A received 5 days of daily prednisolone at $0.5 \mathrm{mg} / \mathrm{kg}$ at the onset of an URTI while group B received 5 days of placebo. Both groups were followed up for one year and the URTI induced relapse frequency was noted. A cross over was performed during the next year, with group A receiving placebo and group B receiving prednisolone.

Results - Thirty-three patients completed the study. In the treatment group 115 episodes of URTI led to 11 relapses while in the control group 101 episodes of URTI led to 25 relapses. There was no significant difference between the mean number of URTIs between the treatment and control groups. The treatment group had significantly less relapses compared to the control group $(\mathrm{p}=0.014)$. Within the treatment group $65.6 \%$ did not relapse whilst the remainder had a single relapse. In contrast only $40.6 \%$ of the control group remained in remission whilst $40.6 \%$ suffered a single relapse and $18.8 \%$ had two or more relapses.

Conclusion - Prescribing a short course of daily corticosteroids during an URTI significantly reduces the frequency of URTI induced relapse in patients with steroid responsive NS who are off corticosteroid therapy. 


\section{Introduction}

Childhood nephrotic syndrome (NS) is the most common glomerular disease affecting children worldwide, with an incidence of 2 to 7 per 100,000 children and a prevalence of about 16 per 100,000 children [1,2]. The incidence is much higher in Asian children. The disease follows a relapsing and remitting course in most children. Over $90 \%$ of patients have steroid-sensitive disease, most having minimal change on histology [1]. Relapses may be associated with life threatening complications e.g. infection, thrombosis and acute renal impairment secondary to hypovolaemia, leading to significant morbidity and rarely mortality [3]. Frequent relapses will also predispose to exposure to multiple courses of high-dose corticosteroids with their inherent side effects. Various strategies have evolved over the years in an effort to reduce relapse frequency. The use of tapering dose regimens and maintaining prednisolone at a dose of $0.1-1 \mathrm{mg}$ per $\mathrm{kg}$ have proved effective in maintaining remission in those relapsing frequently [4]. Numerous steroid-sparing agents such as levamisole, cyclosporine A, cyclophosphamide, mycophenolate mofetil (MMF), chlorambucil and more recently rituximab, have been used with varying success rates in patients with significant steroid induced adverse effects $[4,5,6]$.

Relapses are frequently precipitated by viral upper respiratory tract (URTI) infections $[7,8]$. It is presumed that the $\mathrm{T}$ lymphocyte up-regulation and cytokine release that accompanies an URTI mediates the occurrence of a relapse [9]. Numerous cytokines have been implicated in this regard, namely interleukins 2, 4 and 13[10]. It is also thought that immunosuppressive medications like prednisolone and cyclosporine induce remission and prevent relapse through their effects on cytokine release.

Due to the inherent morbidity that accompanies a relapse, strategies have been sought that reduce URTI induced relapses. Mattoo et al [11], Abeyagunawardena et al [12], and Gulati et al [13] in their studies from Saudi Arabia, Sri Lanka and India respectively, demonstrated a reduction in relapse frequency using a strategy that involved a small, short term increase in the dose of prednisolone at the onset of an URTI in patients with steroid dependent nephrotic syndrome (SDNS) who were on alternate-day corticosteroids. The success of this strategy is indeed important as the ultimate steroid 
burden is significantly reduced. The literature however did not reveal any such studies in patients with steroid-sensitive nephrotic syndrome (SSNS) who are off corticosteroids.

This study was therefore designed as an extension to the previous study by the same authors [12] in order to test the hypothesis that a short course of low dose corticosteroids, through its presumed effects on cytokine release, will reduce URTI associated relapse frequency in patients with SSNS who are off corticosteroids in the context of a randomized placebo-controlled crossover trial. What makes this study unique is that patients referred from the entire country were reviewed by the same team at a single centre which is the largest paediatric nephrology unit in Sri Lanka. Reviewing all NS patients enrolled from the entire country by a single team cannot be easily replicated elsewhere.

\section{Patients and Methods}

\section{Study population}

Patients were enrolled from the paediatric nephrology clinic at Teaching Hospital, Peradeniya, a tertiary nephrology referral centre in Sri Lanka. Sequential patients aged between 2 and 18 years who had been steroid dependent previously, in whom steroids had been tapered and stopped, and who were off steroids for a minimum of three months were considered for inclusion into the study. Patients who were receiving second line agents such as levamisole, cyclosporine A, cyclophosphamide or MMF were excluded. Those parents who anticipated difficulty in attending an outpatient clinic during the course of a viral URTI, and patients who had a renal histology other than minimal change disease were also excluded. All procedures performed in the study were in accordance with the ethical standards of the Scientific and Ethics Committee, Faculty of Medicine, University of Peradeniya and with the 1964 Helsinki declaration and its later amendments or comparable ethical standards. Informed, written consent was obtained from the parents and/or the patients where appropriate, prior to enrolment.

\section{Study design}

The study design was a randomized double blind placebo-controlled cross over trial. At the time of enrolment in the study, the patients were randomized into two groups using the envelope method. 
Group 1 patients were provided a bottle labelled Drug A containing 100 5mg tablets and Group 2 patients received Drug B containing 100 5mg tablets. Both groups of patients and the investigators were blinded to the contents of their medication until the end of the study. All parents were trained to test early morning samples for urine protein excretion and were educated to record it on a daily basis in the record book provided. Urine protein excretion ++ or more for 3 consecutive days was diagnostic of relapse. Viral infections were defined as the presence of 2 or more of the following criteria with clinical, biochemical or microbiological evidence.

1. Fever more than $38^{\circ} \mathrm{C}$

2. Runny nose

3. Cough

4. Body aches, lethargy or loss of appetite

5. Sore throat

All parents were advised to contact the principal investigator or the other 2 members of the team in the event of any febrile illness or at the first sign of a presumed URTI for a telephone consultation. If the predetermined criteria to diagnose a viral URTI were met, these children were advised to take medicine A or B containing either prednisolone or placebo at $0.5 \mathrm{mg} / \mathrm{kg}$ (dose rounded up to the nearest $5 \mathrm{mg}$ ) for 5 consecutive days. The patients were subjected to a clinical examination by the principal investigator or one of the other 2 members of the team or by the local general practitioner arranged by the principal investigator to confirm the viral infection. If the clinical examination or the investigations performed revealed an infection other than a simple viral URTI, the drug therapy was stopped and it was treated accordingly with antibiotics. Such episodes were not considered as viral URTI. All patients were routinely reviewed on day 7 , focusing on the relapse of proteinuria and any potential adverse events due to the modest dose of prednisolone. Relapse of NS was treated with the standard relapse regimen of prednisolone $60 \mathrm{mg} / \mathrm{m}^{2} /$ day until remission and $40 \mathrm{mg} / \mathrm{m}^{2}$ on alternate day for 28 days while keeping these patients in the study.

Both groups were followed up for a period of one year by the principal investigator reviewing them monthly, focusing on the viral URTI's, urine protein excretion and the adherence to the instructions. Thereafter a crossover was performed for the next year with patients in Group 1 being provided with 
drug B and Group 2 receiving drug A to be taken during viral URTI. The code was broken only at the end of the study. The placebo and prednisolone was supplied by SLP (Pvt) Ltd Sri Lanka.

The patients who failed to report with viral infections, did not maintain urine protein excretion records on a daily basis or patients who failed to take the drug during infections as per instructions were excluded from the final assessment of the study. The patients who relapsed frequently and needed regular immunosuppressive therapy were also excluded.

The student t-test was used to compare continuous variables while the Fisher's exact test was used to compare categorical variables. A p value of $<0.05$ was considered significant.

\section{Results}

The study commenced in January 2011 and a total of 48 patients were recruited within 3 months. The randomization allocated 27 patients to group 1 and 21 patients to group 2. Of the 48 enrolled, 33 patients completed the study while15 patients were excluded. Of those excluded twelve were due to non-compliance and three needed maintenance immunosuppressive therapy and were thus not considered in the analysis. In Group 1, the 19 patients who completed the study received prednisolone for the first year of observation and placebo for the second year. In Group 2, the 14 patients who completed the study received placebo for the first year and prednisolone for the second year. The study was completed in 2 years. There were 21 males and 12 females. The age at entry to the study ranged from 2.6- 15.5 years with a median of 6.4 years. Study characteristics are summarised in tables 1 and 2.

In the treatment group 115 episodes of URTI led to 11 relapses (9.5\%) while in the control group 101 episodes of URTI led to 25 relapses (24.75\%) (Figure 1).

There was no significant difference between the mean number of URTIs between the treatment and control groups $(\mathrm{p}=0.673)$. However, patients in the treatment group had significantly fewer relapses compared to the control group ( $\mathrm{p}=0.014)$. The majority $(66.7 \%)$ in the treatment group did not relapse, while the remainder had a single relapse. In contrast, only $42.4 \%$ of the control group remained in remission, $39.4 \%$ suffered a single relapse and $18.2 \%$ had two relapses. The difference in the number 
of patients who did not relapse, 22 in the treatment group and 14 in the control group, also reached statistical significance $(\mathrm{p}=0.049)$.

\section{Results}

The study commenced in January 2011 and a total of 48 patients were recruited within 3 months. The randomization allocated 27 patients to group 1 and 21 patients to group 2 . Of the 48 enrolled in the study of which 33 patients completed as 15 were excluded. Twelve were due to non-compliance. Three needed maintenance immunosuppressive therapy and were not considered in the analysis. In Group 1, 19 patients who completed the study received prednisolone for the first year of period of observation and placebo for the second year. In Group 2, 14 patients who completed the study received placebo for the first year and prednisolone for the second year. The study was completed in 2 years. There were 21 males and 12 females. The age at entry to the study ranged from 2.6- 15.5 years with a median of 6.4 years. Study characteristics are summarised in tables 1 and 2.

In the treatment group 115 episodes of URTI led to 11 relapses while in the control group 101 episodes of URTI led to 25 relapses (Figure 1).

There was no significant difference between the mean number of URTIs between the treatment and control groups $(\mathrm{p}=0.673)$. However, patients in the treatment group had a significantly fewer relapses compared to the control group $(\mathrm{p}=0.014)$. The majority $(66.7 \%)$ in the treatment group did not relapse, whereas the remainder had a single relapse. In contrast, only $42.4 \%$ of the control group remained in remission, $39.4 \%$ suffered a single relapse and $18.2 \%$ had two relapses. The difference in the number of patients who did not relapse, 22 in the treatment group and 14 in the control group, also reached statistical significance. $(\mathrm{p}=0.049)$. The 101 episodes of URTI in the placebo group were associated with 25 relapses $(24.75 \%)$ compared to 115 episodes associated with 11 relapses $(9.5 \%)$ in the treatment group. 


\section{Discussion}

The results of this study indicate that short courses of daily corticosteroids, commenced at the onset of an URTI, reduce the relapse frequency in patients who were previously steroid dependant, and in whom corticosteroid therapy have been omitted for a minimum period of 3 months.

The role of viral URTI in precipitating relapse is thought to occur via the accompanying lymphocyte activation and cytokine release $[9,14,15]$. Toll like receptors (TLR) in the respiratory epithelium are activated by viral URTI, which results in expression of several genes responsible for encoding several cytokines. Tumour necrosis factor alpha, IL-1, IL-6, IL-8 and IL-18 have been identified as common cytokines released in this manner [16]. Corticosteroids are known to affect $\mathrm{T}$ lymphocyte function [17] and especially suppress the production of IL-6 [18]. Apart from the above action on the immune system, glucocorticoids can directly affect glomerular cells. Electron microscopic examination and immune-blot staining has revealed glucocorticoid receptors in all glomerular cells [19]. One or both of these actions may be utilized in NS.

Three studies in the literature looked into a strategy whereby a small increase in the dose of corticosteroids during an URTI was used to reduce relapse frequency $[11,12,13]$. All three studies demonstrated a significant reduction in relapse frequency. These studies included patients with steroid dependent disease who were already on alternate day corticosteroids. Our study population included patients with more stable disease who were not receiving corticosteroids.

The results of this study confirm that this strategy could also be used in this group of patients. No patient relapsed in the absence of URTI and this observation probably reflects the relative stability of disease in patients enrolled in the study.

The previously reported URTI induced relapse frequency is approximately $50 \%$ for patients with steroid dependent disease $[12,13]$. In this study the URTI induced frequency of relapses was much lower $(24.75 \%)$ in the control group. This could be explained by the fact that our patients were not taking corticosteroids, indicating more stable disease which tends to improve with age.

Moreover, two previous studies in the published literature demonstrate that children receiving long term prednisolone therapy are at risk of developing adrenal axis suppression, and are at greater risk of relapse [20,21]. The relatively less relapse frequency in this study group following URTI $(24.74 \%)$ 
could be explained by possible recovery from adrenal axis suppression once they stopped steroid therapy.

This study does have limitations. Principally, the observed high dropout rate was due to failure to report an URTI or as a result of being non-compliant with the medication. This led to the treatment group being somewhat larger $(n=19)$ than the placebo group $(n=14)$ during the first year of the study. Childhood NS tends to improve with age. But the advantage of natural improvement in this study population was counterbalanced because a larger number of patients (group B) received placebo in the second year, such that the advantage of natural improvement in the second year was on the placebo group. Therefore in the second year there was no collective advantage of treatment and natural improvement on a single group. Hence the apparent advantage of natural improvement with age would be nullified, because the older group receiving treatment in the second year is actually smaller than the placebo. Moreover, there might have been instances that a URTI would not have triggered a full relapse in some patients, negating the need for steroid therapy for such episodes. However, as we did not encounter significant side effects with this regimen we believe that this increase in steroids can be justified.

\section{Conclusion}

Administration of five days of daily corticosteroids at $0.5 \mathrm{mg} / \mathrm{kg}$ at the onset of an URTI significantly reduces the frequency of relapses in patients with SSNS, who have not been taking corticosteroids, possibly through prevention of lymphocyte up regulation and cytokine release. This strategy may obviate the need for a course of high dose corticosteroid therapy and therefore reduce potential adverse drug related effects.

Conflict of Interest: The authors declare that they have no conflict of interest. 


\section{References}

1. The primary nephrotic syndrome in children (1981) Identification of patients with minimal change nephrotic syndrome from initial response to prednisone. A report of the International Study of Kidney Disease in Children. J Pediatr 98:561-4.

2. Eddy AA, Symons JM (2003) Nephrotic syndrome in childhood. Lancet 362:629-39.

3. Tarshish P, Tobin JN, Bernstein J, Edelmann CM Jr. (1997) Prognostic significance of the early course of minimal change nephrotic syndrome: Report of the International Study of Kidney Disease in Children. J Am Soc Nephrol 8:769-76.

4. Hodson EM, Craig JC, Willis NS (2005) Evidence-based management of steroid-sensitive nephrotic syndrome. Pediatr Nephrol 20:1523-30.

5. Abeyagunawardena AS, Dillon MJ, Rees L, van't Hoff W, Trompeter RS (2003) The use of steroid sparing agents in steroid-sensitive nephrotic syndrome. Pediatr Nephrol 18:919-24.

6. Ravani P, Rossi R, Bonanni A, Quinn R., Sica F, Bodria M, Pasini A, Montini G, Edefonti A, Belingheri M, De Giovanni D, Barbano G, Degl'Innocenti L, Scolari F, Murer L, Reiser J, Fornoni A and Ghiggeri G. (2015) Rituximab in Children with Steroid-Dependent Nephrotic Syndrome: A Multicenter, Open-Label, Noninferiority, Randomized Controlled Trial. J Am Soc Nephrol 26:2259-2266. doi: 10.1681/ASN.2014080799.

7. Macdonald N, Wolfish N, Maclane P, Phipps P, Rossier E (1986) Role of respiratory viruses in exacerbations of primary nephrotic syndrome. J Pediatr 108:378-82.

8. Moorani KN (2011) Infections are common cause of relapse in children with nephrotic syndrome. Pak Paed J 35:213-9 
9. Yap H, Cheung W, Murugesu L, Sim SK, Seah CC, Jordan SC (1999) Th1 and Th2 cytokine mRNA profiles in childhood nephrotic syndrome: evidence for increased IL-13 mRNA expression in relapse. J Am Soc Nephrol 10:529-37.

10. Hulton SA, Shah V, Byrne MR, Morgan G, Barratt TM, Dillon MJ (1994) Lymphocyte sub populations, interleukin-2 and interleukin-2 receptor expression in childhood nephrotic syndrome. Pediatr Nephrol 8:135-39.

11. Mattoo TK, Mahamoud MA (2000) Increased maintenance corticosteroids during upper respiratory infection decrease the risk of relapse in children with nephrotic syndrome. Nephron 85:343-5.

12. Abeyagunawardena AS, Trompeter RS (2008) Increasing the dose of prednisolone during viral infections reduces the risk of relapse in nephrotic syndrome: A randomized controlled trial. Arch Dis Child 93:226-8.

13. Gulati A, Sinha A, Sreenivas V, Math A, Hari P, Bagga A. (2008) Daily corticosteroids reduce infection-associated relapses in frequently relapsing nephrotic syndrome: A randomized controlled trial. Clin J Am Soc Nephrol 6:63-9.

14. Uwaezouke SN (2015) Steroid-sensitive nephrotic syndrome in children: triggers of relapse and evolving hypotheses on pathogenesi. Ital J Pediatr 41:19

15. Noah TL, Henderson FW, Wortman IA, Devlin RB, Handy J, Koren HS, Becker S (1995) Nasal cytokine production in viral acute respiratory infection of childhood. J Infect Dis 171:584-92.

16. Manjarrez-Zavala ME, Rosete-olvera DP,Gutierrez-Gonzalez LH, Ocadiz-Delgado R, Cabello-Gutiérrez C. Pathogenesis of viral respiratory infections. In: Vatz M eds. Respiratory disease and infection-A new insight. London: InTech 2013 
17. Herold MJ, McPherson KG, Reichardt HM (2006) Glucocorticoids in T cell apoptosis and function. Cell Mol Life Sci 63:60-72.

18. Waage A, Slupphaug G, Shalaby R (1990) Glucocorticoids inhibit the production of IL6 from monocytes, endothelial cells and fibroblasts. Eur J Immunol 20:2439-43.

19. Yan K, Kudo A, Hirano H, Watanabe T, Tasaka T, Kataoka S, Nakajima N, Nishibori Y, Shibata T, Kohsaka T, Higashihara E, Tanaka H, Watanabe H, Nagasawa T, Awa S (1999) Subcellular localization of glucocorticoid receptor protein in the human kidney glomerulus. Kidney Int 56:65-73.

20. Abeyagunawardena A, Hindmarsh P, Trompeter R (2007) Adrenocortical suppression increases the risk of relapse in nephrotic syndrome. Arch Dis Child 92:585-588.

21. Leisti S, Koskimies O (1983) Risk of relapse in steroid-sensitive nephrotic syndrome: Effect of stage of post-prednisone adrenocortical suppression. J Pediatr 103:553-557.

\section{Tables and Figures}


Table 1 - Results and characteristics of group 1 (First year prednisolone; second year placebo)and group 2 (First year placebo; second year prednisolone).

\begin{tabular}{|c|c|c|}
\hline Patient data & $\begin{array}{c}\text { Group 1 } \\
\text { (First year } \\
\text { prednisolone; second } \\
\text { year placebo) }\end{array}$ & $\begin{array}{c}\text { Group 2 } \\
\text { (First year placebo; } \\
\text { second year } \\
\text { prednisolone) }\end{array}$ \\
\hline Number of patients & 27 & 21 \\
\hline Excluded patients & 8 & 7 \\
\hline Number of patients who completed the study & 19 & 14 \\
\hline Gender & $\begin{array}{l}\text { Males }=12 \\
\text { Females }=7\end{array}$ & $\begin{array}{l}\text { Males }=9 \\
\text { Females }=5\end{array}$ \\
\hline Mean age at entry (years) & 12.3 & 9.9 \\
\hline Mean age at the $1^{\text {st }}$ episode of NS (years) & 4.6 & 3.5 \\
\hline $\begin{array}{l}\text { Mean duration of NS prior to randomization } \\
\text { (years) }\end{array}$ & $7.5 \pm 2.3$ & $6.4 \pm 2.4$ \\
\hline Number of URTI during the $1^{\text {st }}$ year & $68($ Mean $3.6 \pm$ SD 1.6) & $\begin{array}{l}41 \text { (mean } 2.9 \pm \mathrm{SD} \\
1.5)\end{array}$ \\
\hline Number of URTI during the $2^{\text {nd }}$ year & $60($ mean $3.2 \pm$ SD 1.4$)$ & $\begin{array}{l}47 \text { (mean } 3.4 \pm \mathrm{SD} \\
1.4)\end{array}$ \\
\hline Number of relapses during the $1^{\text {st }}$ year & 7 (mean $0.4 \pm$ SD 0.5$)$ & $9($ mean $0.6 \pm \mathrm{SD} 0.6)$ \\
\hline Number of relapses during the $2^{\text {nd }}$ year & $16($ mean $0.8 \pm$ SD 0.8$)$ & $4($ mean $0.3 \pm \mathrm{SD} 0.5)$ \\
\hline $\begin{array}{l}\text { Mean annual steroid dose during } 1^{\text {st }} \text { year } \\
(\mathrm{mg} / \mathrm{kg} / \mathrm{year})\end{array}$ & $\begin{array}{l}21.84 \\
(\mathrm{IQR}=7.50-47.50)\end{array}$ & $\begin{array}{l}29.82 \\
(\mathrm{IQR}=5.00-45.00)\end{array}$ \\
\hline $\begin{array}{l}\text { Mean annual steroid dose during } 2^{\text {nd }} \text { year } \\
(\mathrm{mg} / \mathrm{kg} / \mathrm{year})\end{array}$ & $\begin{array}{l}37.37 \\
(\mathrm{IQR}=7.50-77.50)\end{array}$ & $\begin{array}{l}18.39 \\
(\mathrm{IQR}=7.50-40.00)\end{array}$ \\
\hline
\end{tabular}


Table 2 - Summary of results with respect to treatment and placebo groups

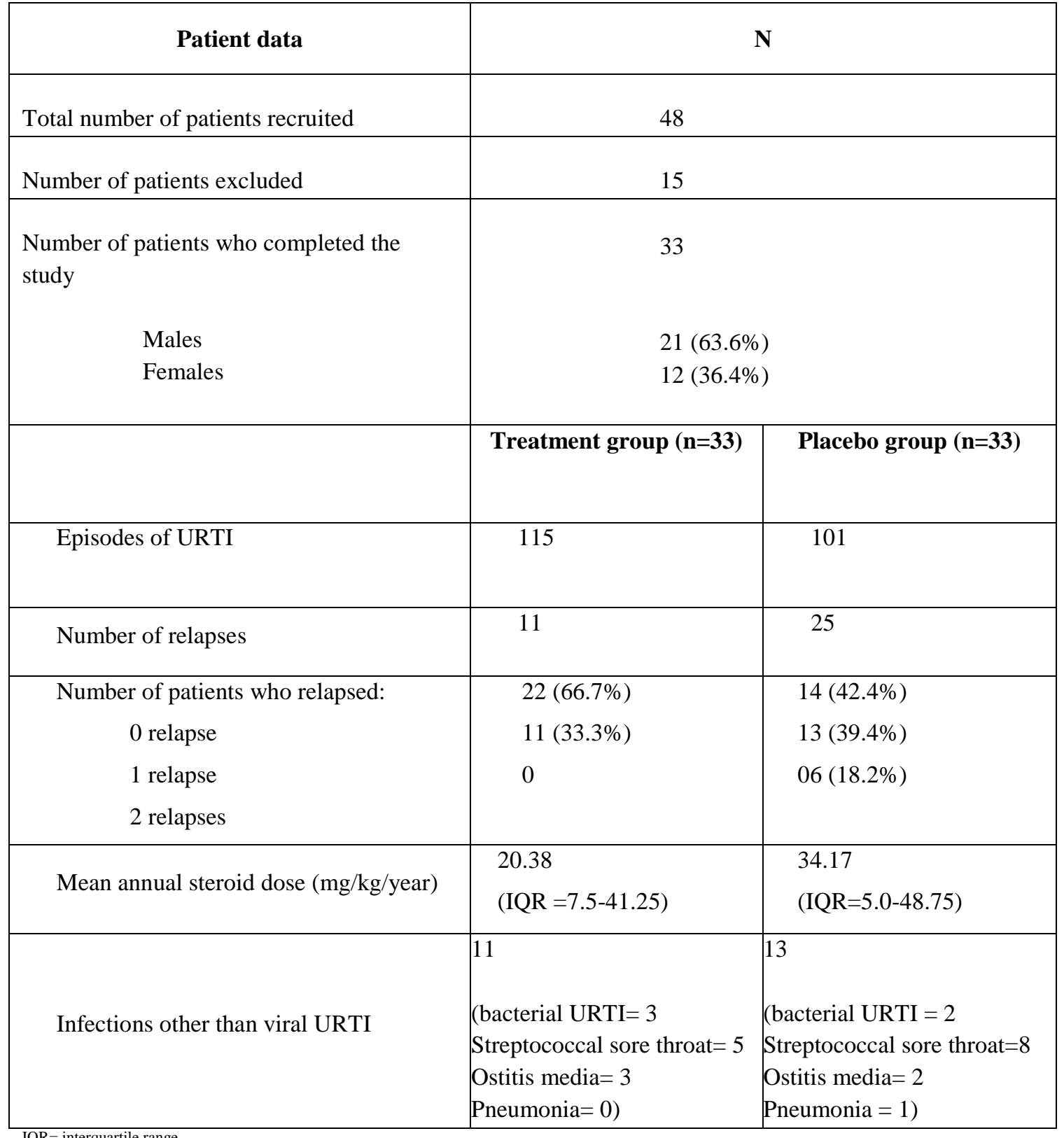

$\mathrm{IQR}=$ interquartile range 


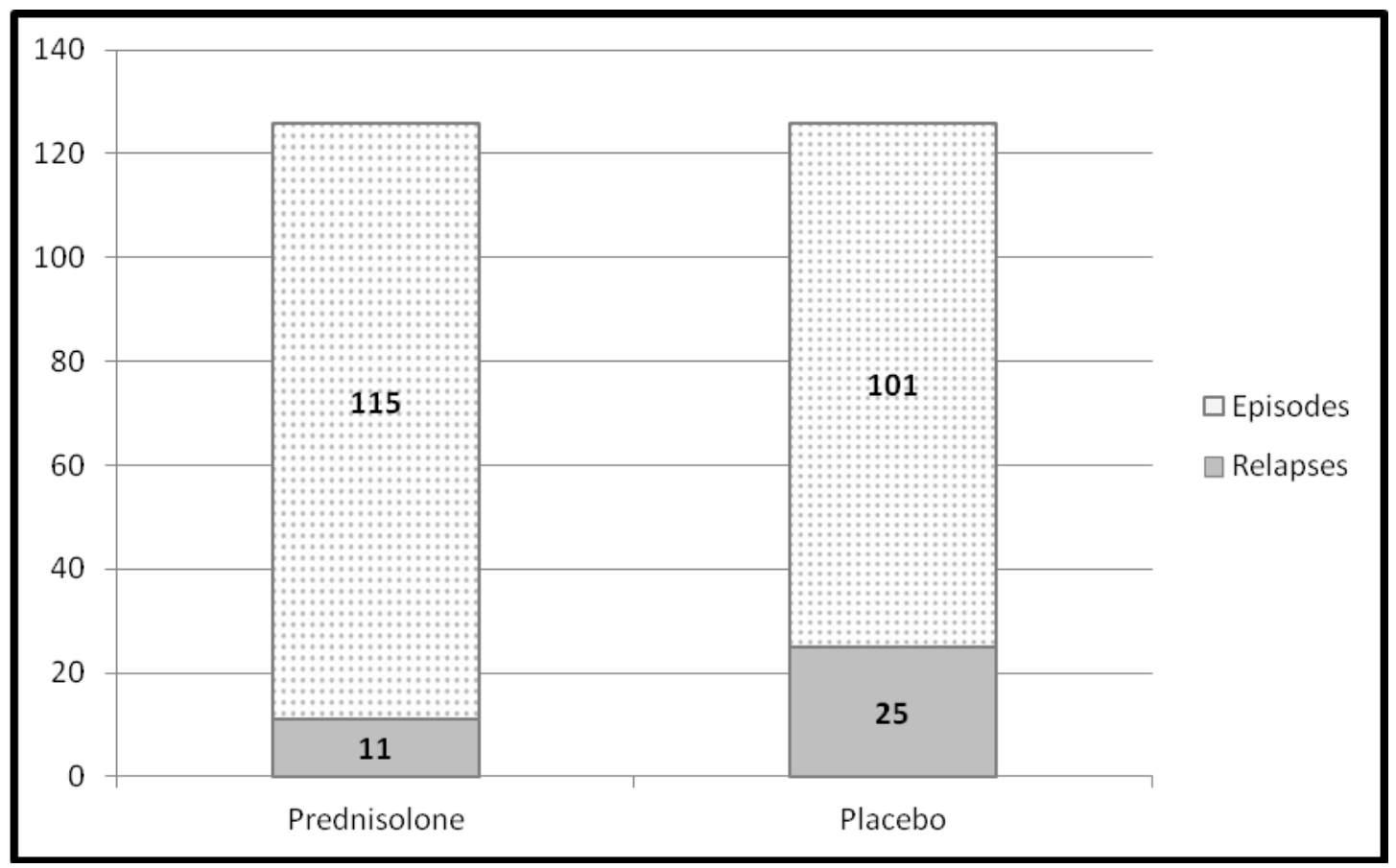

Figure 1 - Comparison of URTI episodes and relapses in the prednisolone treatment group and control group 